\title{
HAUDRICOURT, André-Georges. Des gestes aux techniques : Essai sur les techniques dans les sociétés pré-machinistes
}

\section{Fabiano Campelo Bechelany}

\section{(2) OpenEdition Journals}

Édition électronique

URL : http://journals.openedition.org/aa/233

DOI : $10.4000 / a a .233$

ISSN : 2357-738X

Éditeur

Programa de Pós-Graduação em Antropologia Social (UnB)

\section{Édition imprimée}

Date de publication : 1 décembre 2012

Pagination : 247-251

ISSN : 0102-4302

\section{Référence électronique}

Fabiano Campelo Bechelany, « HAUDRICOURT, André-Georges. Des gestes aux techniques : Essai sur les techniques dans les sociétés pré-machinistes », Anuário Antropológico [En ligne], v.37 n.2 | 2012, mis en ligne le 01 octobre 2013, consulté le 28 avril 2021. URL : http://journals.openedition.org/aa/233 ; DOI : https://doi.org/10.4000/aa.233

\section{(c) $)(9)$}

Anuário Antropológico is licensed under a Creative Commons Atribuição-Uso Não-Comercial-Proibição de realização de Obras Derivadas 4.0 International. 


\section{HAUDRICOURT, André-Georges. 2010. Des gestes aux techniques: Essai sur les techniques dans les sociétés pré- machinistes. Textes presenté et commenté par Jean- François Bert. Paris: Edition de la Maison des sciences de l'homme; Édition Quae. 236 pp.}

Fabiano Campelo Bechelany

PPGAS/UnB

Autor ainda pouco conhecido do público brasileiro, a julgar pela ausência de traduções acessíveis no país, André-Georges Haudricourt (1911-1996) foi um pesquisador francês de obra vasta, que atravessou campos diversos como a etnobotânica, a linguística, a história, a zoologia, a agronomia e a etnologia. Suas contribuições para os estudos da técnica são decisivas, tendo publicado dois livros fundamentais sobre o tema (L'homme et les plantes cultivées, em colaboração com Louis Hédin, 1943; e L'homme et la charrue à travers le monde, em colaboração com Jean-Brunhes Delamarre, 1955), além de dezenas de artigos, os principais reunidos na coletânea La technologie sicience humaine, de 1988. Teve passagens pela Rússia - onde trabalhou com o botânico Nicolas Vavilov - e pelo Vietnã; na França trabalhou no Museu Nacional de História Natural e se tornou diretor de pesquisa honorário no CNRS, por onde passou primeiro pelo Departamento de Botânica, depois pelo de Linguística. Compreender a importância da interdisciplinaridade em sua obra é condição para entender a etnologia que praticou, a transposição de métodos entre disciplinas, e o potencial de suas comparações e de sua abordagem da técnica.

Des gestes aux techniques: Essai sur les techniques dans les sociétés pré-machinistes, publicado em 2010 na França, busca disponibilizar textos inéditos ou pouco conhecidos da obra deste autor, no mesmo momento em que se publicam outros trabalhos em torno da herança de Haudricourt e demais pioneiros do campo da antropologia da técnica (ver, p. ex., Penser le concret, org. Noël Barbe e J-F. Bert. Paris: CREAPHISEditions, 2011). Des gestes aux techniques apresenta em forma definitiva diferentes versões de estudos, que começaram a ser redigidas em 1946, encontrados nos arquivos de Haudricourt (reunidos no Institut Mémoires de l'Édition Contemporaine - Imec) a respeito do ato técnico e sua força motriz. 
Jean-François Bert teve o trabalho de cotejar os manuscritos, alguns corrigidos por Haudricourt mesmo após tê-los publicado. O texto definitivo vem ainda acrescido de passagens de outras versões, que nos permitem acompanhar a evolução de seu trabalho. Soma-se ao Essai sur les techniques dans les sociétés pré-machinistes, um conjunto de artigos importantes, publicados em periódicos e outras obras, que nos oferece um panorama de algumas questões caras ao autor ao longo da sua trajetória.

Trata-se de uma coletânea de escritos importantes para a compreensão da antropologia da técnica francesa, redigidos por um de seus principais formuladores. Mas, ademais de um interesse histórico, os escritos presentes no livro trazem uma abordagem focada no estudo das materialidades, dos gestos corporais e das técnicas que proporciona certas aproximações instigantes com perspectivas contemporâneas da antropologia. Por exemplo, várias das análises de Haudricourt associam-se de modo frutífero a um movimento atual na disciplina em direção ao que é adjacente ao homem, ou seja, um deslocamento da identificação do que lhe é próprio, para análises centradas na complexidade do concreto, dos objetos, enfim, para usar um termo muito em voga atualmente, dos não humanos que compõem o universo social.

Tais aspectos da relação do homem com o meio e as coisas ao seu redor são matéria de escrutínio na tradição antropológica da técnica desenvolvida principalmente na França, tradição esta que lança suas raízes nos trabalhos desenvolvidos por Marcel Mauss sobre o tema, o mais conhecido deles sendo "As técnicas do corpo" (para outros textos de Mauss a respeito da técnica, ver a coletânea Techniques, Technology and Civilization, Berghahn Books, 2006, organizada por Nathan Schlanger, com recente tradução para o francês, pela PUF, 2012). Mas é principalmente na pena de alguns de seus alunos que essa linha de estudos se desenvolveu teórica, metodológica e etnograficamente, destacando-se entre eles André Leroi-Gourhan e o próprio Haudricourt.

Des gestes aux techniques contém diferentes facetas da obra de Haudricourt, aqui voltadas para a análise das técnicas propriamente ditas. A perspectiva adotada pelo autor parte da abordagem empírica das técnicas, apontando diversas conexões com os trabalhos atuais na disciplina, sobretudo aqueles que têm buscado tratar das relações entre humanos e não humanos visando repensar o crivo epistêmico da matriz cultura/natureza. Isto porque, guardando as especificidades do plano teórico de sua época, a análise de Haudricourt não opera por uma generalização dos domínios de distribuição dos entes, como sujeito/objeto e seus derivados, mas está centrada nas ações que ocorrem na interação entre humanos, animais, plantas e coisas. 
Em se tratando do Essai, que constitui a primeira parte do livro, há aqui um programa de pesquisa de grande escopo, que vai das técnicas desenvolvidas a partir do corpo humano (tido como a origem da força motora) àquelas que se desenvolvem a partir de forças exteriores ao homem. O texto se inicia com "O motor humano", passa pelo andar; a natação; o subir, trepar; o carregar, portar; percutir e lançar; empurrar e puxar; as armadilhas, como modos de reservar a energia; do movimento retilíneo ao movimento circular; a utilização de animais domésticos; a utilização da água; a utilização do vento. O ponto central na abordagem das atividades é que o método de Haudricourt não parte da análise dos objetos, mas "do motor que faz com que a ferramenta seja eficaz" - como enfatiza J-F. Bert. Este é o objeto central da perspectiva analítica de Haudricourt: trata-se de estudar a origem e a forma das forças motrizes nas suas diferentes manifestações em uma sociedade.

Seu ponto de vista se situa no ato técnico, nos gestos concretos e na energia empregada, acompanhando seu desenvolvimento na evolução das técnicas. O objeto técnico é considerado a partir do gesto que o envolve, que o produz e o faz funcionar, de modo que Haudricourt busca enfatizar as ações e as relações que o objeto enfeixa, assim como sua eficácia quanto a um objetivo proposto. Não se trata, portanto, de uma observação dos fins externos (instrumentalismo) ou dos produtos de uma técnica (utilitarismo), nem de qualquer forma de determinismo a priori - tem-se aqui uma análise interna das relações implicadas no gesto técnico, ou seja, das diversas formas de ação (humanas ou não) inferidas nos atos técnicos.

Sua análise das técnicas de base (as técnicas do corpo), das ferramentas fabricadas que operam como exteriorizações dos gestos (lançadores, ou cestos, p. ex.), das técnicas em que a força humana é concretizada em outros elementos (armadilhas), ou da utilização de outras forças exteriores (as velas dos barcos que utilizam o vento, ou os animais domésticos como força de tração, p. ex.) concretiza-se em relação a outros aspectos que envolvem a sua realização. Tomemos sua análise da marcha em diferentes sociedades. Focando a caça, e recusando a classificação simplista entre sociedades agricultoras, pastoras, coletoras, caçadoras etc., Haudricourt aponta semelhanças no ato de caminhar entre as sociedades que baseiam suas técnicas de aquisição na caça e na coleta. Técnica que depende eminentemente do motor humano, o andar na caça é intensivo e extensivo, mas pode variar segundo os atributos da presa.

O uso de armas ou armadilhas altera a distância do confronto e, consequentemente, da caminhada para o abate. Mas é preciso distinguir ainda outros aspectos, como os diferentes modos de deslocamento: se são caças coletivas ou não; o deslocamento de homens do de mulheres; os deslocamentos distintos para cada 
idade. Seria preciso ainda considerar o andar da caça em relação aos demais andares de uma sociedade, como o andar cotidiano de uma casa a outra, p. ex. Como em Mauss, a miríade de aspectos implicados no ato de caminhar em uma sociedade motiva Haudricourt a considerá-la como um "fenômeno social total” (:47).

Em se tratando das forças externas ao homem empregadas nos atos técnicos, o caso da domesticação de animais é exemplar para compreendermos essa multiplicidade da técnica, porque ela implica modos de ação sobre espécies animais que variam quanto à atividade pretendida e às possibilidades de alimentá-los e criá-los em cativeiro, reunindo portanto dimensões que podem ser tidas como ecológicas e sociais. Tendo em vista sua utilização como força de tração, ou como transporte, cada espécie tem desempenhos variados. Haudricourt desenvolve, assim, uma perspectiva relacional, que busca ver o conjunto de relações que uma técnica envolve. Dessa forma, é preciso que a análise leve em conta a mediação social, dos vínculos dos homens entre si, nas interações técnicas.

Gostaria de resumir aqui três aspectos fundamentais que estão presentes nos textos reunidos em Des gestes aux techniques e que expressam dimensões fundamentais debatidas e analisadas pela antropologia da técnica francesa.

O primeiro deles é a relação entre a técnica e a sociedade. Haudricourt aponta o caráter eminentemente social da técnica sem precisar recorrer às representações, aos simbolismos ou mesmo ao estilo, o que caracteriza, como sabemos, várias das abordagens da cultura material. O essencial é que uma técnica se realiza a partir de modos de relação entre os homens e de relação com a natureza. Além disso, não podemos esquecer que não são as condições biofísicas humanas, nem as condições ambientais, suficientes para que certa técnica seja adquirida, mas é fundamental que haja a mediação das relações humanas, através da qual uma técnica é aprendida e transmitida.

O segundo deles é a noção de invenção e transformação técnica. Haudricourt reconhece a importância das inovações para o progresso técnico. É acompanhando a mudança no emprego da força motriz que o autor acredita poder demonstrar aspectos da evolução das sociedades, o que aponta para uma mudança no potencial de ação sobre a natureza. Mas isso deve ser analisado dentro do contexto geral de uma cultura, seu meio, seus aspectos sociais, suas relações com o corpo. Uma inovação não é predeterminada, mas está ligada às oportunidades que são oferecidas por um contexto de relações entre diferentes entes e materiais. Mesmo colocando em certos momentos o problema em termos de evolução e de energia - aspectos centrais em meados do século XX - a postura internalista e relacional de Haudricourt é totalmente distinta daquelas que foram avançadas, por exemplo, por Julian Steward, Leslie White ou Lewis Mumford. Além do que, sua perspectiva das transformações técnicas dialoga com um interesse 
etnográfico refinado sobre as relações entre os humanos e o ambiente.

A terceira delas, talvez sua principal contribuição para a antropologia, é a ideia de que uma análise antropológica da técnica é antes de tudo uma análise dos modos de ação de uma sociedade. Isso implica considerar, como Haudricourt faz nos textos da segunda metade do livro, uma homologia, ou uma espécie de refração entre um modo de agir concreto, técnico, gestual, de um comportamento material e outras dimensões da vida. O seu clássico "Domestication des animaux, culture des plantes et traitement d'autrui" - que vemos agora traduzido para o português (Série Tradução, n. 7, 2012, Departamento de Antropologia/UnB) dá forma final a uma reflexão desenvolvida por Haudricourt durante anos (os dois artigos que o antecedem no livro são esboços da mesma ideia), na qual ele busca apontar uma distinção entre o par mentalidades e técnicas do Ocidente (Europa e Mediterrâneo) e do Extremo-Oriente (Índia e China). Essa distinção se baseia em dois aspectos: 1. o tratamento em relação ao outro e aos animais, plantas etc.; 2. os modos de "governamentalidade" que permitem designar as diferentes maneiras de conduta dos indivíduos.

Estes aspectos levam o autor a distinguir nas mudanças da relação entre o homem e a natureza que algumas das revoluções técnicas (a domesticação de animais, a descoberta de culturas de plantas alimentares) provocaram transformações na relação entre os homens: sua caracterização de uma mentalidade de agricultor no Extremo-Oriente e de pastores no Ocidente. Ora, essa diferença nos modos de ação, ou de interação (o primeiro determinado por uma "ação indireta negativa”, o segundo por uma “direta positiva”), opera como um esquema de princípios relacionais que se encontra de maneira homóloga na filosofia, na religião e em outros domínios. Não se trata de extensão ou de projeção das relações técnicas para o universo das relações entre os homens, mas de princípios gerais do comportamento que não derivam da natureza dos entes envolvidos.

A atenção que Haudricourt devotou à observação das ferramentas e dos utensílios, a descrição das técnicas ou a análise dos processos de evolução das "forças produtivas" são raras nos dias atuais na pesquisa etnológica. Ainda assim, é preciso notar uma crítica epistemológica importante destes trabalhos. Há na etnologia praticada por Haudricourt uma justaposição de materiais empíricos variados, como nota J-F.Bert. Para um leitor contemporâneo, esse tipo de análise traz o inconveniente de associar realidades muitas vezes complexas das quais esses materiais são retirados. Se a crítica pode ser pertinente para algumas das análises de Haudricourt, estas ainda assim trazem proposições, descrições e correlações significativas, aportando, no mínimo, valiosas intuições metodológicas para uma aproximação das relações estabelecidas por grupos humanos com diversos seres e coisas, sobretudo plantas e animais. 